\title{
Quality Assurance in Higher Education in the Twenty-first Century: Concepts and Challenges
}

\author{
Ben A. Maguad \\ Andrews University, USA
}

\begin{abstract}
The higher educational landscape has been changing due to pressure from both external and internal forces. This pressure stems from institutions operating in an environment characterized by novelty, complexity, uncertainty, and unprecedented advances in technology. Conditions and conventions within this environment are changing at a pace faster than they did in the past. This trend is expected to continue as the twenty-first century continues to unfold. Unfortunately, the existing management structure and culture of higher education make change very difficult. This emanates from the long-held belief that colleges and universities are the preservers, transmitters, and generators of knowledge, and that quality is already practiced within their halls. At any rate, colleges and universities must be sensitive to these environmental changes and be cognizant of their implications to higher education. Existing administrative systems are becoming outmoded and thereby need to be revamped in order to ensure success in a hypercompetitive marketplace.

To navigate the turbulent academic waters of the twenty-first century, institutions of higher learning will need to redefine educational quality by considering viewpoints from their various stakeholders. While there may be no single definition of quality that meets the expectations of all stakeholders, an attempt can be made to define the criteria that each stakeholder group uses when judging quality and then to take these competing views into account when assessing educational quality. Moreover, a framework, like the education criteria for performance excellence discussed in this paper, is needed in order to help the college or university to understand and assess how well it is accomplishing what is important to the institution, how well administration addresses its needs, how well deployed its processes are, how good the results are, and whether the organization is learning and improving.
\end{abstract}

\section{Introduction}

The environment in which institutions of higher learning operate is changing dramatically. Social, cultural, economic, political, technological, and other systems associated with this environment have undergone profound and rapid changes. Educational systems, which are inevitably intertwined with these other systems, have had to respond to these changes in order to ensure that the quality of life of its stakeholders is maintained and developed.

Many institutions of higher learning today are facing formidable challenges: sky-rocketing operating costs, spiraling tuition fees, hyper-competitive marketplace, declining student demand, and many others. The standard response by many has been to cut cost by cutting non-basic services, laying off employees, and curtailing education and training of personnel. By doing these repeatedly, administrators have become experts in managing crises, in dealing with quick fixes, and in providing simple, short-term solutions to problems which do not seem to go away. Amidst all these, a question may be asked: "Is there a better way to manage higher education to deliver superior quality performance and maintain a high level of stakeholder satisfaction?"

Quality, as it is traditionally defined in higher education, is increasingly being challenged by many outside academia. However, many of those involved in academia believe that quality is already being practiced. Many colleges and universities still hold, even today, the historic view that they are the preservers, transmitters, and generators of knowledge. This view, however, conflicts with what the general public expects of their graduates with regards to the job-related value of higher education. Thus, there seems to be a disconnect between what higher education produces in terms of learning and outcomes and what industry requires [1]. "We are buying instruction and service and higher education is selling research" [2].

Changing economic conditions have also caused concern among the general public about career opportunities and economic well-being. The argument is that education is not just a social concern but a major economic issue as well. The quality of education that our students receive today will help determine the competitiveness of our companies tomorrow. More and more people today believe that access to higher 
education is a means toward employment and economic security.

Students, parents, legislators, employers, and other stakeholders are bringing a customer orientation to their assessment of higher education. They expect of higher education what they demand elsewhere: better service, lower costs, higher quality, and a range of products that satisfy their own perception of what a good education ought to be [3]. This customer orientation has helped to facilitate the outcomes assessment movement in higher education.

Perception of quality in higher education has diminished. This loss of confidence is partly due to the perceived tendency of colleges and universities to protect their own disciplines and culture without sufficient regard to the requirements and expectations of their stakeholders. This may be summed up by the expressions that they might be "for quality" but in many eyes they "do not do quality".

Higher educational institutions have begun to realize that they are operating in an era characterized by increasing complexity, novelty, uncertainty, and advances in technology never previously imagined and experienced. These forces have helped to increase the gap between the quality desired by people and the quality of products and service being delivered. Technology has enabled stakeholders to compare the quality of other educational systems with their own, subsequently causing the "quality desired" curve to rise at an accelerating pace.

\section{Quality concepts in higher education}

There are as many approaches to defining quality in education as there are in defining quality of a manufactured product or delivered service [4]. The differences in approaches make it very difficult to develop a common approach to educational quality. Even after decades of debating the virtues of quality in the educational area, there still seems to be no commonly accepted standards. Even though each individual may have some understanding of what quality might be, the concept remains difficult to explain. Quality continues to exhibit an elusive character which, in many cases, is often determined by how one believes his or her personal needs and expectations have been met. The following summarizes some of the different concepts that have been used to assess quality in higher education.

\subsection{The traditional concept}

Quality is traditionally associated with the provision of a product or service that is unique and outstanding and which bestows special status on the owner or user. Such high standards of quality can only be attained at a very high cost to the user. In higher education, this is often associated with most people's perception of the world's top-notch universities in terms of the "distinctive and special student experience that they provide, and in terms of the graduate and research output" [5]. However, if we were to apply this criterion to all institutions of higher learning, most would be rated low quality. This is the major drawback of the traditional concept when employed to assess quality in higher education as a whole.

\subsection{Conformance to specifications or standards}

A quality product or service is one that conforms to a specification or standard. The term "standard" is used as a "yardstick" or a basis for measuring a required characteristic of a product or service. Applied to higher education, this definition provides all institutions an opportunity to strive for quality as different standards can be set for different institutions.

This model, however, has a number of drawbacks. It says nothing about the criteria utilized to develop the standards. A product or service may conform to standards but will still be perceived as low quality if the standards do not meet the expectations of the user. The model also implies that once a standard is set, it does not need to be reconsidered. This is somewhat unrealistic because in the real word, as society changes, standards may need to be revised to reflect current circumstances. Moreover, the model implies that standards are easily measurable. This may not be the case in higher education where the term standard may be defined in different ways. For example, what does "excellence in higher education" mean? There still seems to be no consensus as to how it should be defined. Another example is what do we mean by the expression "standards are dropping"? Could it mean that the level of achievement needed to pass a course has been watered down? Could it also mean that students are achieving a lower level of performance although the standards remain the same?

\subsection{Fitness for purpose}

This is the definition of quality favored by most analysts and policymakers in higher education. Quality is gauged in terms of whether or not a product or service meets its stated purpose or purposes.

This definition of quality has distinct advantages over previous models. First, it allows for the determination of the specification of a product or service. Second, it allows for reconsideration of the suitability of the specification over time. Third, it 
allows the application of quality analysis of higher education at various levels.

One drawback of this model pertains to the lack of consensus on what the purpose or purposes of higher education should be. One critical question is who should define the purpose or purposes of higher education. Another possibility is for higher education to have different purposes some of which run into conflict with each other.

\subsection{Effectiveness in achieving institutional goals}

This concept focuses on evaluating quality at the institutional level. An institution is said to have high quality if it clearly states its mission (or purpose) and is efficient and effective in meeting the goals that it has set for itself. This model is broader than the "fitness for purpose" definition and includes other areas such as effective management and resource usage efficiency in the evaluation of quality in higher education.

Each individual institution determines its own definition of quality and standards and puts into place its own quality assurance system. An audit committee is then set up to check whether the institution successfully achieves its stated goals and objectives.

\subsection{Meeting customer stated or implied needs}

This definition of quality places high emphasis on identifying and meeting customer needs. The customer future needs are translated into measurable characteristics and then products or services are designed and delivered at a price the customer will pay. Using this definition in higher education poses a number of difficulties. Questions remain as to who the customer of higher education is or who should define quality in higher education. For instance, taking the student as customer poses a number of difficulties especially in the academic area. Although student needs can be identified and met, the quality of student experience goes beyond this. At the heart of the educational experience is the relationship between professors and students in the teaching and learning process. Both professors and students are essential components of the academic production process. They assume either the role of producer or customer depending on the circumstances. One major criticism of this model is that students as customers may not be always qualified to determine what quality is or whether it is present.

\section{Defining quality in higher education}

There is no single, all-encompassing definition of quality that meets the needs of all stakeholders in higher education. Different stakeholder groups have different priorities and needs. Although their understanding of quality may differ, they may not necessarily be right or wrong. In view of this, quality should not be considered as a unitary concept but a multiple one. To achieve this, we should define as clearly as possible the criteria that each stakeholder group uses when judging quality and then take these competing views into account when assessments of quality are undertaken.

A comprehensive and useful definition of quality should include all four sets of criteria described below. These four sets of criteria must be considered equally important in developing a modern of quality for higher education [6].

\subsection{Input criteria}

These criteria focus on the nature and level of resources available to the institution like the characteristics of incoming students, credentials of faculty, size of library, structure and availability of physical facilities, and the amount of financial reserves. For many years, the input criteria have been the most commonly identified measures of quality. Many accrediting agencies have used input measures to measure quality like the quality of entering students, number of books in the library, quality of graduate degrees held by faculty, number of square feet of classroom space, student-faculty ratio, and others. Many people believe that if you put good things together something good will come out of it. This concept of education is often associated with traditional high-status institutions.

\subsection{Output criteria}

These criteria stress the nature and extent of institutional products like the characteristics of graduating students, success of alumni, research and scholarly publications, and public service. They build on the assumption that institutions of higher education are accountable to society for what they produce. In recent times, the reputation and quality of educational institutions are increasingly being determined on the basis of their demonstrated outcomes.

\subsection{Value-added criteria}

These criteria zero in on the differences that an institution has made in the growth of all of its 
members: intellectual, moral, social, vocational, physical, and spiritual. Based on these criteria, the quality of an institution would be judged by the extent to which it is effective in developing the talents of its students from whatever level they were at when entering to the time they finish college.

\subsection{Process-oriented criteria}

These criteria include the level and manner of participation of all appropriate constituencies (or stakeholders) in the educational, administrative, and governance processes of the institution, including the defining and assessing of quality. Based on these criteria, it is not what we do or what we accomplish that makes for quality; rather, it is the way in which we do what we do and how we decide what to do that differentiate a high-quality education.

As described above, the four sets of criteria must be considered equally important in developing a modern definition of quality for higher education. Quality may thus be defined as follows:

Quality is the extent to which an institution successfully directs adequate and appropriate resources (input) to the accomplishment of its mission-related outcomes (output) and that its programs make a significant and positive difference in the lives of people associated with it (value-added) and that these programs are created, conducted, and modified in line with the mission and values of the institution (processoriented).

\section{Assuring quality in higher education}

One way to assess quality in higher education is by using the Baldrige Excellence Framework (7). The education criteria for performance excellence are designed to help the college or university to understand and assess how well it is accomplishing what is important to the institution, how well administration addresses its needs, how well deployed its processes are, how good the results are, and whether the organization is learning and improving. The criteria consist of seven categories described as follows:

\subsection{Leadership}

Leadership is the overriding principle of quality improvement. Without it, total implementation of quality at the college will not succeed. Managing for quality requires positive change, and leadership is the catalyst to effect and manage such change. The role of administrators should be one of enabling everyone in the institution to focus on pleasing its stakeholders. They develop work processes, measurements, and goals for the whole institution and inspire everyone to seek quality in all aspects of their work in order to accomplish these goals. It is, therefore, imperative, for administrators to show a clear understanding of the mission, vision, and values of the institution and ensure that others buy into the same mission and vision.

It is primarily the top administration's responsibility to keep the process going for they have the requisite authority, vision, and constancy of purpose to direct the whole institution at the strategic level. They must strive to create an atmosphere in which excellence will thrive and which stresses not only competencies and skills but also patience, kindness, and mutual respect.

Administrators must model behaviors they want everyone in the institution to exhibit. True quality leaders would exhibit deep integrity and a noble character which fosters trust. Trust in turn leads to collaboration rather than competition. Trust fosters a learning environment where mistakes are tolerated and used as lessons for improvement. The key to developing a trusting environment is the leader's unshakeable fairness in dealing with issues that are discussed in public and in private.

A true quality leader would communicate openly and frequently with those with whom he or she interacts. His or her communication would be constructive, truthful, thoughtful, and careful and performed with the highest possible integrity. He or she would seek to understand the effects of his or her actions on the institution. A quality leader would be personally involved in the training and education of himself or herself as well as others in the institution.

The role of the college or university Board should not be understated. The Board must demonstrate total commitment and support for the institutional quality improvement program. It can help set the stage for new administrative policies and procedures that would enhance the institutional quality process and, through solid education and training, can become true champions for educational quality.

\subsection{Strategy}

Strategic planning begins with a firm commitment and affirmation from the administrators that it will no longer be "business as usual" in the institution. This process requires participation from everyone. Total participation is possible if discussions concerning the strategic plan takes place within the context of a trusting and open environment where all can express their views without fear of retribution or reprisal especially from those in authority. Strategic planning 
establishes goals which must relate directly to the mission of the college or university. A specific time frame is given for achieving such goal. When a strategic plan (what to improve) is done well and linked firmly with the operating or process capabilities (how to improve) of the institution, the results can be astounding.

The strategic plan must be communicated and deployed with great care because how it is disseminated tells a lot about the depth of administrative commitment. Plans must be reviewed on a regular basis to keep up with rapidly changing stakeholder requirements and market conditions. The planning process itself must be reviewed with an eye toward continuous improvement.

\subsection{Customers}

Customer or stakeholder satisfaction is the real measure of whether or not the goals of the college or university are being met. It is the culmination of the institution's quality improvement efforts. It is the single best means to communicate quality. The most vital step on the road to customer/stakeholder satisfaction is understanding their requirements identified through a systematic data collection. Data must be collected responsibly to resolve problems and improve the educational system. The more highquality data the college or university uses, the clearer its customer/stakeholder portrait will be, the faster it will be able to adapt to changes in the marketplace, and the better it will be in anticipating the needs of its customers. Data, however, should not be used for the purpose of blaming or "casting stones" on anyone. Unless it is used responsively to resolve problems, there is no valid reason for collecting it. In qualitybased institutions, complaints are eagerly sought after as golden opportunities to learn and improve the educational system.

\subsection{Measurement, analysis, and knowledge management}

Adequate and accurate data and information are necessary to drive quality excellence and improve competitive performance. They are needed to improve the institution's stakeholder focus, services, and internal operations. The main reason for collecting them is to improve the institutional administrative and academic processes and systems. Data are essential for effecting quality improvement because the latter can never be achieved without the former.

Every piece of data collected from various stakeholders must be carefully analyzed and presented in a way that is readily understood by all. Every piece of data ought to be considered because no one would provide information if it will just be ignored or overlooked. All relevant information should be shared with members of the institution so that they too can become winners and partners in change.

When data, statistics, and information are used systematically, they will give the college or university a focus for change. They will allow the institution to plan effectively and make the necessary process changes. Data collection and information analysis must become an indispensable part of the institutional never-ending cycle of process improvement.

\subsection{Workforce}

An effective workforce recruitment and utilization will need to address the following areas: (a) recruitment of dedicated and qualified personnel; (b) total involvement in quality improvement efforts; (c) employee education and training; (d) recognition and measurement of exceptional performance; and (e) morale and well-being of employees. These areas are interconnected. Recognition, for instance, boosts participation and morale while training facilitates participation.

To encourage college-wide participation and involvement, the college can take the following steps to engage all its workers in a number of ways. First, institute a vigorous program of education and selfimprovement. Education in the principles of quality management is critical to producing quality work. Second, remove barriers that rob people of their right to pride in workmanship. Recognize that everyone wants to do quality work. Provide challenges that would require them to stretch their limits. When people feel no one cares about their work, pride in workmanship disappears and work becomes a drudgery. No one is happy and no one seems to really care. Consequently, nothing of quality happens. Third, institute a vigorous program of self-improvement. Leaders especially the top administration should become role models for continuous self-improvement both in their personal and professional lives. Each individual should develop a personal development plan which includes, for example, conference or seminar attendance, subscription to professional magazines, journals, and newspapers, and keeping up with the latest trend in one's subject matter. Fourth, improve constantly using the principles, methods, and tools of quality until all have achieved a degree of success and are doing quality work.

One very important aspect of human resource utilization is team building which is almost as important as process improvement itself. The synergy developed within effective teams in terms of relationship, trust, and support can exceed the original expectations of the team. To maximize team 
involvement and effectiveness, the institution must create an ideal environment which fosters team cohesion and where people feel comfortable, confident, and motivated.

\subsection{Operations}

The purpose of process management is to ensure that all important processes - from academic processes to support processes and to other operations of the institution - work together to maximize its effectiveness. Effective process management is mostly about the prevention of errors. It requires institutional personnel to know how to monitor, control, and constantly improve processes by using methods that focus on quality instead of mere numerical goals and outcomes. Lasting and significant change will require the participation of those in the "front-line" of activity. In this regard, professors and students have significant roles to play in the quality improvement process. They are the ultimate innovators in the college or university. In quality-based institutions of higher learning, educators recognize that those directly involved in the activity are the ones most qualified to suggest ways to improve the system.

\subsection{Results}

Quality and operational results are the bottom line. They help the institution to assess the quality of its academic and administrative systems. If particular systems produce good results, chances are they are good systems. Results also demonstrate that the institution is measuring and tracking its systems. They verify progress toward customer satisfaction. Since the goal of quality management is continuous improvement, the only true way to measure that improvement is by the use of data collected from the institution's internal and external customers before and after changes are made to the processes and systems. Data collection will give a more accurate picture of what is working and which systems and processes require improvement.

The institution should never lose sight of the importance of feedback from its customers or stakeholders. Feedback based on fact is vital if the college or university is to truly embark on a continuous improvement journey. It is only through systematic and factual collection of data that the college can truly know whether or not the job is being done right. Total quality management after all requires that the information be gathered and used solely for purposes of continuous improvement.

\section{Conclusion}

Quality, as higher education traditionally defines it, is being challenged by many outside academia especially by those who believe that access to higher education is a means toward employment and economic security. This gives rise to a major question: How should quality be defined and who is qualified to define it? As discussed earlier in the paper, there can be many approaches to defining quality in higher education which makes it difficult to develop a common approach to educational quality. In view of this, this paper proposes a systems approach whereby quality is defined in terms of four sets of criteria: input, output, value-added, and process-oriented. Using these criteria, quality may thus be defined as "the extent to which an institution successfully directs adequate and appropriate resources (input) to the accomplishment of its mission-related outcomes (output) and that its programs make a significant and positive difference in the lives of people associated with it (value-added) and that these programs are created, conducted, and modified in line with the mission and values of the institution (processoriented)".

Developing a common approach to educational quality is a necessary first step to assuring quality in higher education. The next step is to assess it using a framework like the Baldrige Excellence Framework. The education criteria for performance excellence are designed to help the college or university to understand and assess how well it is accomplishing what is important to the institution, how well administration addresses its needs, how well deployed its processes are, how good the results are, and whether the organization is learning and improving. It is through systematic and factual collection of data that the college or university can truly know whether or not the job is being done right and that the information is used solely for the purpose of continuous improvement.

\section{References}

[1] Seymour, D., On Q: Causing quality in higher education, MacMillan Publishing Company, New York, 1992.

[2] Lewis, R.G. and D.H. Smith, Total quality in higher education, Florida, St. Lucie Press, Florida, 1994.

[3] Zemsky, R., W. Massy, and P. Oedel, "On Reversing the Ratchet”, Change, May-June 1993, 25, 3, p. 7.

[4] Rinehart, G., Quality education, ASQC Quality Press, Wisconsin, 1993 
[5] Green, D., "What is quality in higher education? Concepts, policy and practice", What is quality in higher education?, Open University Press, Great Britain, pp. 3-20.

[6] Bergquist, W.H., Quality through access, access with quality, Jossey-Bass Publishers, California, 1995.

[7] Evans, J.R., Quality and performance excellence: Management, organization, and strategy $\left(8^{\text {th }}\right.$ ed.), Cengage Learning, Boston, 2017. 